\title{
The conditioning regime in industrial drying of Scots pine sawn timber studied by X-ray computed tomography: a case-study
}

\author{
José Couceiro $^{1}\left[\right.$ - Lars Hansson ${ }^{2} \cdot$ Margot Sehlstedt-Persson $^{1} \cdot$ Tommy Vikberg $^{3} \cdot$ Dick Sandberg $^{1}$
}

Received: 26 April 2019 / Published online: 20 June 2020

(c) The Author(s) 2020

\begin{abstract}
Industrial drying of sawn timber is a process driven by a difference in moisture content (MC) between the core and the surface as moisture moves from the wet inner region towards the drier surface. After drying, the timber surface is always drier than its core, and stresses have developed within the wood volume. If the timber is to be further processed, these stresses and the moisture gradient need to be reduced to avoid unwanted distortion, i.e. the timber needs to be conditioned. Conditioning is usually accomplished by exposing the timber to a hot and humid climate after the drying regime. The conditioning regime is essential for timber quality, and it is energy and time consuming; therefore of interest for optimisation. This research was a case study where for the first time the MC during conditioning was studied in an X-ray computed tomography (CT) scanner. The aim was to test a previously developed algorithm and investigate the influence of MC and heartwood-sapwood proportion on the effectivity of the moisture equalisation in $30 \mathrm{~mm}$ thick Scots pine boards. The MC was estimated from CT data acquired during the drying and conditioning of the boards in a lab-scale kiln adapted to a medical CT scanner. Results show that the algorithm can provide relevant data of internal MC distribution of sawn timber at the pixel level. Furthermore, for the drying schedules studied, the conditioning at low MC (8\%) does not need to be longer than $3 \mathrm{~h}$, while higher MC (18\%) requires a longer conditioning.
\end{abstract}

\section{Introduction}

Wood drying is a vital process in sawmilling to reduce the moisture and achieve a high-quality sawn-timber product. An important procedure in the final stage of the drying process is the so-called conditioning regime, which is highly important to achieve an even moisture content (MC) distribution in the timber and to reduce the stresses developed during the drying that causes distortion of the sawn timber in further processing. Effects of a large MC gradient and the remaining stresses in the timber are often seen in products that are obtained by splitting sawn timber longitudinally after drying, such as facade panelling or flooring. The

José Couceiro

jose.couceiro@1tu.se

1 Wood Science and Engineering, Luleå University of Technology (LTU), Skellefteå, Sweden

2 Department of Ocean Operations and Civil Engineering, Norwegian University of Science and Technology (NTNU), Ålesund, Norway

3 RISE - Research Institutes of Sweden, Bioeconomy, Biobased Materials, Skellefteå, Sweden conditioning regime consists in raising the relative humidity $(\mathrm{RH})$ in the kiln and keeping a constant climate for an equilibrium $\mathrm{MC}$ slightly higher than the target, meaning that the $\mathrm{MC}$ in the surface region of the timber increases, thus reducing the $\mathrm{MC}$ gradient. The time to complete suitable conditioning decreases with increased temperature and $\mathrm{RH}$, but usually, industrial facilities are limited in this regard by their energy-capacity, thus the need for research adjusted to the industrial conditions.

Besides moisture equalization, the development of internal stress in the sawn timber during drying makes it necessary to perform conditioning to increase mechano-sorptive creep and thereby eliminate internal stresses. Already in early stages of drying, the timber surface dries below the fibre saturation point (FSP) well before the core does, creating the so-called dry shell (Wiberg 1996). This dry shell intends to shrink, but as it is restrained by the wetter core of the sawn timber that keeps it under tension, it creeps instead due to mechano-sorptive, elastic and viscoelastic behaviour (Moren and Sehlstedt-Persson 1993), a phenomenon known as casehardening (McMillen 1958). Later during drying, when the core also dries below FSP, it also intends to shrink, but it is now restrained under tension by the dry shell 
that crept before, stress that would remain if not corrected (Morén 2016). When drying turns into the conditioning regime, and the RH raises, the direction of the moisture diffusion flow in the drier wood surface region is reversed, and the absolute value of the moisture flow increases: the wood surface goes from being slowly drying to quickly absorbing water. This triggers once again the mechano-sorptive creep (Moren and Sehlstedt-Persson 1993) in the outer parts of the timber, now under compression, stress is released because the core remains almost unchanged, the overall moisture gradient in the cross section decreases and, ideally, the timber becomes stress-free and moisture equalised. Even though the conditioning regime increases the MC of the surface, the inner core of the timber continues to dry with a moisture flow directed towards the surface. If not performed correctly, there is a risk of excess over-conditioning of the sawn timber, which results in a moisture gradient in the inverse direction (wetter surface than core) and also in the development of stresses that could result in surface checking during cooling. To avoid distortion when the sawn timber is further processed, it must ideally be completely free from stresses.

In large Scandinavian sawmills, there are nowadays two main types of methods to perform the conditioning regime: using pressurised water spraying system or using saturated water vapour. Rising the RH with water vapour results in conditioning that is performed under the diffusion regime, while conditioning with saturated water vapour would cause condensation at the surface of the timber. Both have been widely used, and in fact, conditioning with saturated water vapour is more effective but very energy consuming, i.e. in industrial conditions, it usually requires a steam boiler with a power of the order of $2 \mathrm{MW}$ for a kiln with a batch volume of $100-150 \mathrm{~m}^{3}$. The most common industrial method nowadays is conditioning with pressurised hot water spraying nozzle system forming small droplets (aerosol), which facilitates evaporation.

Further optimisation of the conditioning regime will improve not only the quality of the sawn timber but also the management of a sawmill in terms of energy savings and avoidance of bottlenecks in the production flow. It is nevertheless a stage of wood processing that has not been investigated in depth. Chen et al. (1997) suggest three alternative procedures to relieve remaining stresses: cooling under a cover, so the condensation water moistens the timber surfaces, steaming without previous cooling, or intermittent drying and conditioning. Their experiments were based on previously developed simulation models, and they conclude that the three options provide similar results for radiata pine. More recently, He and Wang (2015) studied the moisture equalization of sawn timber, which does not necessarily mean stress relief, and they posted three different ways theoretically possible to equalize the moisture distribution in timber: by increasing the $\mathrm{MC}$ of the surface, by reducing the $\mathrm{MC}$ of the core, or by a combination of these methods. They state that reducing the MC of the core without modifying the MC of the outer regions is not applicable. They studied a method based on microwaves that reduces the MC of the core while increasing that of the surface based on the difference in the level of microwave energy absorbed by the wetter inner core and the dryer outer region. They claim that microwave conditioning could be applied industrially (Sethy et al. 2016), but even though some results are indeed promising, nothing indicates that the implementation of microwave-based systems in industrial softwood drying plants in northern Europe would be competitive.

A large part of the existing research is based on computer simulations that allow quick results. To study improvements in the conditioning through simulations, Salin (2001) established a criterion for a good conditioning based on the accuracy of the final average MC level of the sawn timber in relation to the target $\mathrm{MC}$ level, on the final internal distribution of $\mathrm{MC}$ and on the measurement of the slicing test gap (a method to visualize stresses within the cross section of the sawn timber). Such a criterion could nowadays be considered valid as it takes into account those aspects that still concern the industry. Salin (2001) proposes, based on simulations, alternatives to the traditional conditioning regime based on varying climate during the conditioning regime, instead of the traditional constant climate. The proposed schedules have not been tested experimentally, and they would be challenging to implement because it requires a fast rise in both temperature and $\mathrm{RH}$.

This study takes a different approach by studying the conditioning regime in timber drying with CT using a combination of equipment that is, to this day, unique worldwide. In the Luleå University of Technology in Skellefteå, a medical CT scanner is combined with a drying kiln, which allows real-time inspection of the interior of sawn timber specimens and further calculation of density and $\mathrm{MC}$ with a maximum resolution of about $0.1 \times 0.1 \times 1.0 \mathrm{~mm}^{3}$. There is thus no need to stop the drying process and remove the samples to make CT scans, which would create a disturbance on the measurements. According to what can be found in the literature, no other research than that made at the Luleå University of Technology has made use of CT scanner to study drying of timber in real time. Furthermore, no records could be found of such method applied to study specifically the conditioning regime, probably due to the difficulty in studying the diffusion in local regions of the timber because it implies very small variations of MC. Hansson and Fjellner (2013) have developed a specific image-processing algorithm for pixel-wise measurements of MC in CT images. The algorithm uses an image at the MC to be studied and an image of the same region but at totally dry conditions and implements a deformation coefficient in the $x$ and $y$ directions of the scanning plane to compensate for the shrinkage of wood 
during drying. This method allows for calculating accurate values of the $\mathrm{MC}$ in each pixel during the drying process. It must be noted that other methods have been developed to this end, like the one described by Li et al. (2013), which takes into account the deformation of the image by using as reference average values of larger regions of dry and wet wood and water or that developed by Watanabe et al (2012), which has already been evaluated by Couceiro and Elustondo (2015). Sandberg and Salin (2012) make use of the algorithm developed by Lindgren (1992) to calculate $\mathrm{MC}$ using five reference points to perform image registration and compensate the deformation of wood during drying. The algorithm by Hansson and Fjellner (2013) calculates the deformation to each individual pixel through the analysis of the deformation of the area surrounding it instead of from a limited number of manually inserted reference points.

This research presents a case study with the first objective of trying to prove the applicability of the method described by Hansson and Fjellner (2013) to study moisture gradients during the conditioning of sawn timber. The hypothesis is that the method will provide consistent results at the pixel level that will allow the visualization and quantification of the moisture gradient and its changes during the conditioning regime. The second objective was to study how the timber MC at the start of the conditioning regime affects the effectivity of the moisture equalisation with the hypothesis that the lower the MC is, the shorter conditioning is needed to achieve acceptable levels of moisture equalisation. Finally, the third objective was to study the influence of heartwood content in the sawn timber on the conditioning regime, because structural differences in the different chemical composition of heartwood and sapwood results in different diffusivity in moisture transport. Sehlstedt-Persson (2001) shows that the diffusivity of Scots pine heartwood increases after extraction to the same value as sapwood, which remains unchanged. Sehlstedt-Persson (2001) establishes thus that the higher level of extractives in heartwood is a cause of low diffusivity, and therefore the hypothesis in this research was that a high proportion of sapwood would allow a shorter time for the conditioning regime to reach the same level of moisture equalisation.

\section{Materials and methods}

\subsection{Wood material}

Block sawn and un-dried timber (centre yield) of Scots pine (Pinus sylvestris L.) with green-size cross section dimensions of $31 \times 124 \mathrm{~mm}$ was collected from a local sawmill in northern Sweden and used for the study. The boards were selected with clear differences in heartwood content. Each board was divided into $0.7 \mathrm{~m}$ long specimens (Fig. 1), and the cross section was sealed with a heat-resistant sealant (Sikaflex 221) and kept in frozen condition in plastic until the start of the experiment to avoid uncontrolled drying. One pair of specimens was cut from each board so that three pairs of matched specimens could be used in the study. The specimens were thawed in water for $24 \mathrm{~h}$ at room temperature prior to starting the experiments.

\subsection{Equipment}

Scanning of the specimens was made with a medical CT scanner (Siemens Somatom Emotion Duo) using a 300 $\mathrm{mm}$ reconstruction window, which results in a pixel size of $0.6 \times 0.6 \mathrm{~mm}^{2}$. A specially designed laboratory drying kiln that fits within the gantry of the scanner was also used. With this combination of equipment (Fig. 2) it was possible to scan the sawn timber specimens inside of the kiln without interrupting the drying process. The control parameters of the drying kiln were the air velocity, time and the dry- and wet-bulb temperatures.

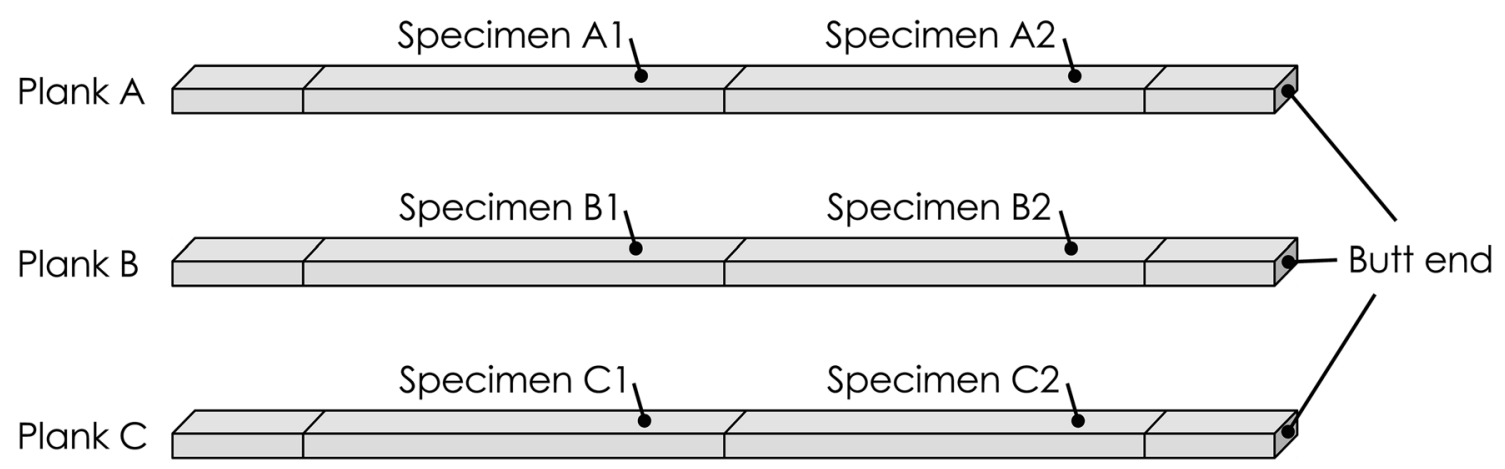

Fig. 1 Six specimens used in the study belonged to three boards (A, B and C) and were marked A1, B1 and C1 for test run No. 1 and A2, B2 and $\mathbf{C 2}$ for test run No. 2 (Table 1) 


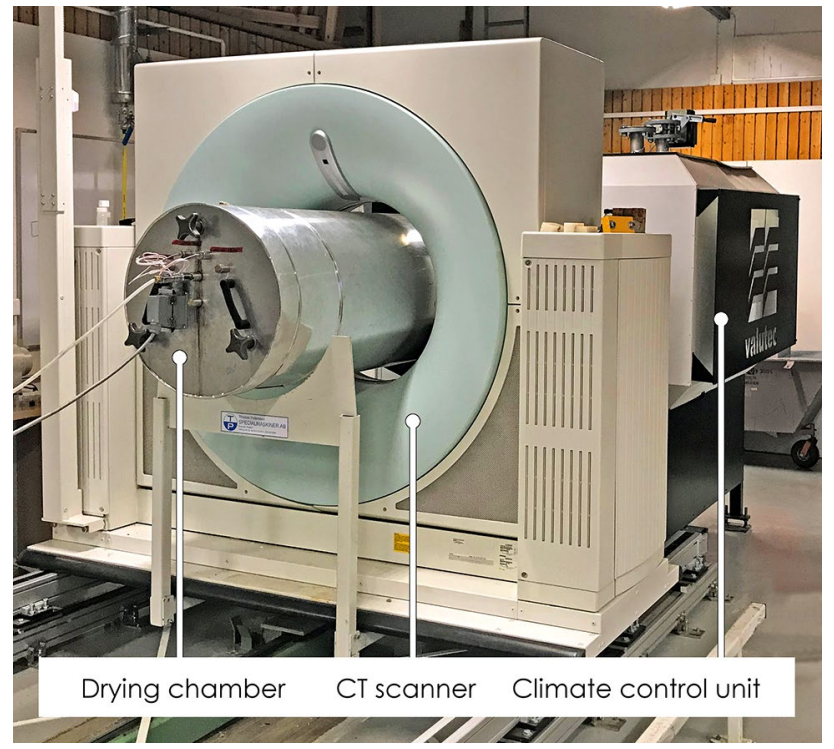

Fig. 2 Medical CT scanner and drying kiln fitted in the gantry of the scanner

\subsection{Test design}

Two test runs with different drying schedules aiming for different target MC were performed (Table 1). In each test run, three specimens were chosen based on the differences in heartwood distribution. Figure 3 shows the cross section at the scanning positions of each specimen through pictures obtained once the experiments were completed. Each specimen in test run No. 1 was matched with another specimen from the same board in test run No. 2 (see Fig. 1). The specimens were placed in the kiln-tube with a gap of about $25 \mathrm{~mm}$ between each other, securing a suitable CT scan position in all three specimens. A CT scan with $5 \mathrm{~mm}$ scanning thickness was made before the start of drying and then every hour during heating and drying regimes. During the conditioning regime, scans were performed every 15 minutes. All scans were done at exactly the same location in the specimen, disregarding longitudinal shrinkage and thus assuming the voxel depth is constant. To calculate the MC in the specimens based on CT data, a scan of the specimens in totally dry condition was also performed. After the conditioning and cooling regimes finished, all samples were dried at $103 \pm 2{ }^{\circ} \mathrm{C}$ until constant weight of the specimens was reached and, afterwards, a final dry $\mathrm{CT}$ scan was made at exactly the same scanning position.
Table 1 Test runs performed with the specimens according to Fig. 1

\begin{tabular}{|c|c|c|c|c|c|}
\hline Test run no. & Drying time (h) & $\begin{array}{l}\text { Conditioning } \\
\text { time (h) }\end{array}$ & Specimen & $\begin{array}{l}\text { Average } \mathrm{MC}(\%) \text { of the } \\
\text { specimen before drying }\end{array}$ & $\begin{array}{l}\text { Heartwood } \\
\text { content (\%) }\end{array}$ \\
\hline \multirow[t]{4}{*}{1} & 48.1 & 7.1 & A1 & 78.5 & 36 \\
\hline & & & B1 & 134.5 & 5 \\
\hline & & & $\mathrm{C} 1$ & 125.7 & 8 \\
\hline & & & Average & 112.9 & \\
\hline \multirow[t]{4}{*}{2} & 89.0 & 7.05 & $\mathrm{~A} 2$ & 68.6 & 47 \\
\hline & & & B2 & 117.4 & 14 \\
\hline & & & $\mathrm{C} 2$ & 133.3 & 5 \\
\hline & & & Average & 106.4 & \\
\hline
\end{tabular}

Heartwood content is area share of heartwood in the scanned cross sections
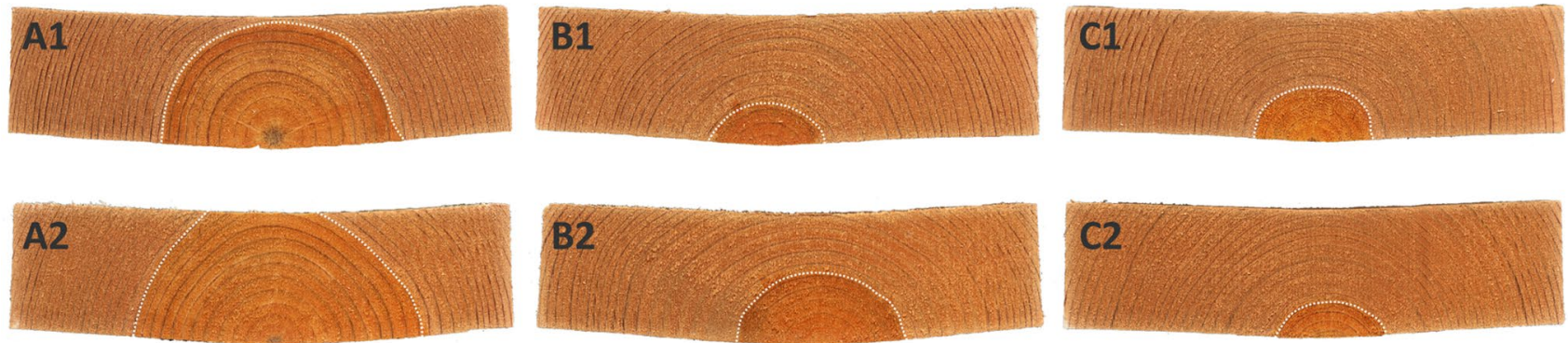

Fig. 3 Cross-section views of the specimens in the location where they were CT scanned. The border between the heartwood (darker hue) and the sapwood is marked with a dotted line. 


\subsection{Drying conditions}

An industrial drying schedule for Scots pine sawn timber of the same dimension as used in this study was applied to the test with a constant wet-bulb temperature of $60^{\circ} \mathrm{C}$ and maximum dry-bulb temperature of $70{ }^{\circ} \mathrm{C}$ (Fig. 4). Throughout the drying and conditioning regimes, constant air speed of $5 \mathrm{~m} / \mathrm{s}$ was used. The drying time was shorter in test run No. 1 (48 h) than in test run No. $2(89 \mathrm{~h})$ because they were estimated for target MC approximately $18 \%$ and $8 \%$, respectively. The conditioning regime was the same in both tests runs, with a quick rise in wet-bulb temperature, a duration of about $7 \mathrm{~h}$ and constant dry- and wet-bulb temperatures of $70{ }^{\circ} \mathrm{C}$ and $68{ }^{\circ} \mathrm{C}$ respectively, corresponding to an equilibrium $\mathrm{MC}$ of approximately $18 \%$.

\subsection{Image registration and dry basis moisture content estimations}

As described by Couceiro (2016), estimation of the dry-basis $\mathrm{MC}$ of wood from CT data requires two images: one at the $\mathrm{MC}$ to be determined and another one at a reference MC which, for practical reasons, usually is $0 \%$. From each image, data of voxel volume and density can be extracted and, thus, mass can be calculated (Lindgren 1992). Applying the same rationale as for the gravimetric method, it is possible to use mass data of the two images to calculate MC. Nevertheless, if such analysis is to be done at the pixel level, image editing is necessary to match the images since wood shrinks and swells with changing MC, and thus, the voxels at a given pixel location in the two images do not correspond to the same regions in the wood specimen (Couceiro 2016).

A method described by Hansson (2007), Hansson and Cherepanova (2012) and Hansson and Fjellner (2013), which is compiled in MATLAB algorithms, was used in this work. Therefore, all analyses here presented were performed in MATLAB. Their method is based on transforming the

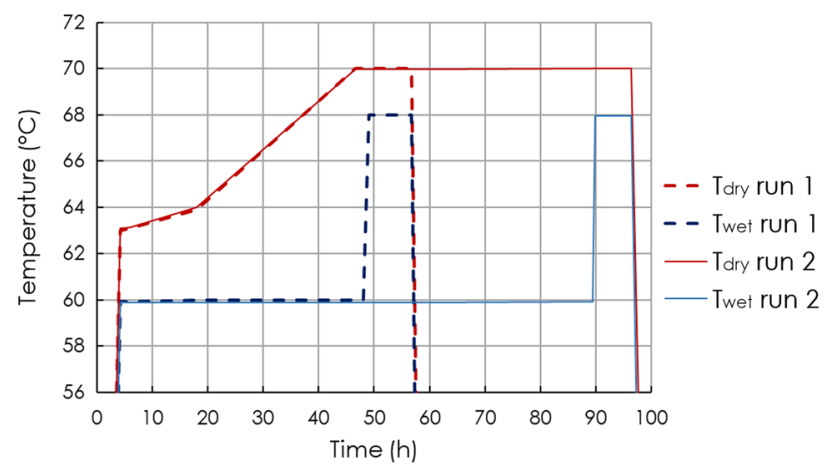

Fig. 4 Drying schedule with the drying process (0-48 h and 0-89 h) and conditioning regime (48-55 h and 89-96 h) used in test run No. 1 and test run No. 2, respectively images taken during drying to the same shape as the image of the completely dry wood specimen, a process called "registration". During this process, each image is considered a deformed version of the dry wood specimen image and the deformation transformations are obtained and reversed by using features in the images given by density variations. By using always the same reference image it is possible to match all the images to a common shape. The method also implements compensation for the deformation so that the correct mass of the wood contained in each voxel can be obtained. The area of a single pixel in an image can be defined by the coordinates of its four corners, which are new theoretical coordinates assigned according to the deformation information of the nearest areas of the image. MC calculations can be performed with the resulting images using the pixels located at the same position in the registered image at the MC to be determined and in the one at the dry state because, after registration and compensation, they correspond to the same wood region. The process is exemplified in Fig. 5. The final result of this process is an image of the wood specimen with the $0 \% \mathrm{MC}$ shape, where each pixel has the MC value (MC image). During the processing, the images are re-sized by nearest-neighbour interpolation to a pixel area of $0.25 \times 0.25 \mathrm{~mm}^{2}$.

\subsection{Analytical method}

There is no standardized method to investigate the difference in $\mathrm{MC}$ in sawn timber cross sections, so an adaptation to CT data of a practical method described by Esping (1988) was used. Esping's method is broadly accepted and used both in industry and in research. It consists of dividing a piece of wood into seven sections (Fig. 6) and using the five central sections to calculate the moisture gradient $\left(\mathrm{MC}_{\text {grad }}\right)$ according to Equation (1).

$\mathrm{MC}_{\text {grad }}=\frac{\mathrm{MC}_{\max }-\mathrm{MC}_{\mathrm{av}}}{\mathrm{MC}_{\mathrm{av}}}$

where $\mathrm{MC}_{\max }$ is the $\mathrm{MC}$ of the section with the highest $\mathrm{MC}$ amongst the central sections (numbered 1-5 in Fig. 6) and $\mathrm{MC}_{\mathrm{av}}$ is the average $\mathrm{MC}$ of those central sections.

The analytical method used in this research is based on Esping's method which is originally a destructive method that would not allow continuous measurement. Ten sections were extracted from the MC images, instead of the five central sections proposed in Esping's method, to have a convenient number of steps in the gradient visualisation and calculation that are described below. Figure 7 shows an example of the ten sections in one of the specimens. The sections are generated by a Matlab function that crops them out of the MC image generated (image (d) in Fig. 5). The relative size of these sections was different 

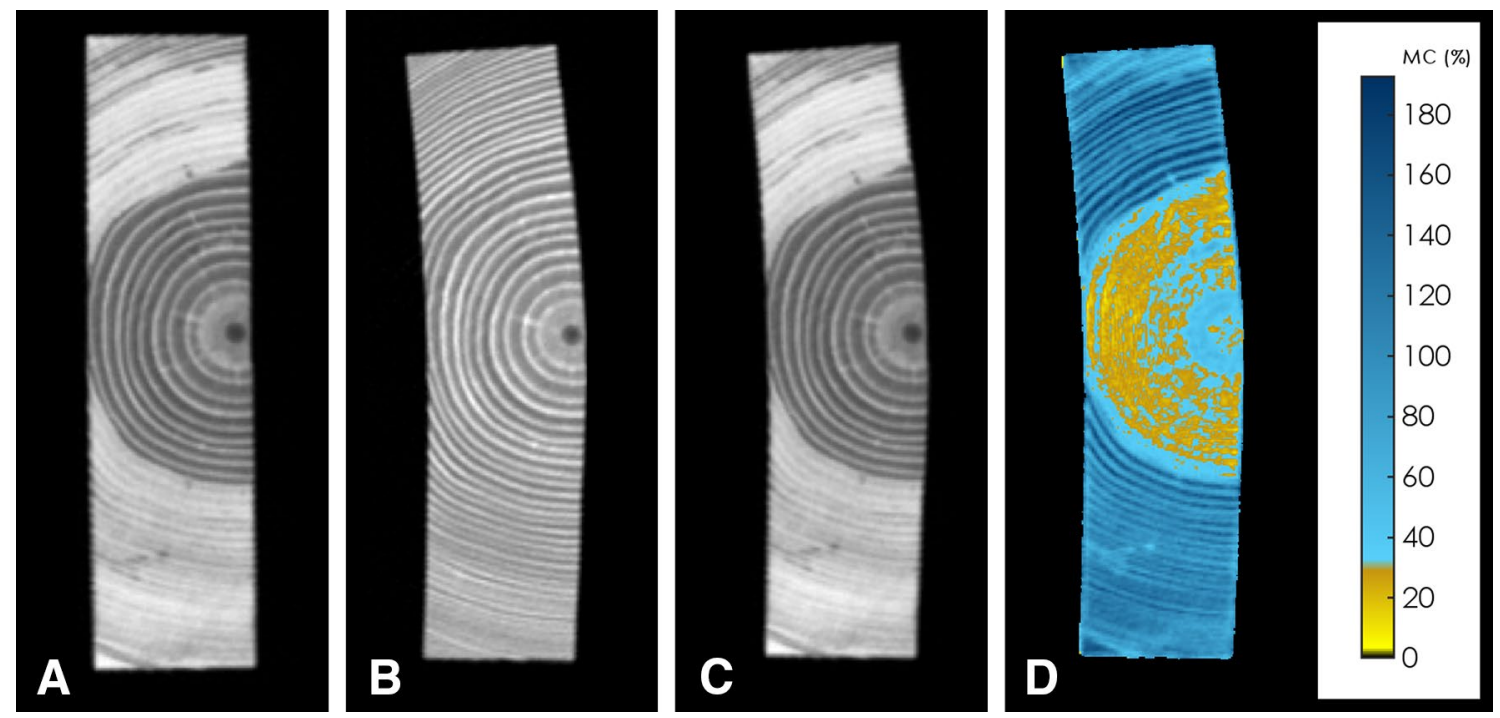

Fig. 5 Registration procedure showing different stages of image processing for pixel-wise dry-basis MC determination of wood based on CT data: a a cross-section view of a wood specimen at the MC to be studied, $\mathbf{b}$ the same cross-section view at $0 \% \mathrm{MC}$, $\mathbf{c}$ the crosssection view in (a) geometrically transformed to match the shape of

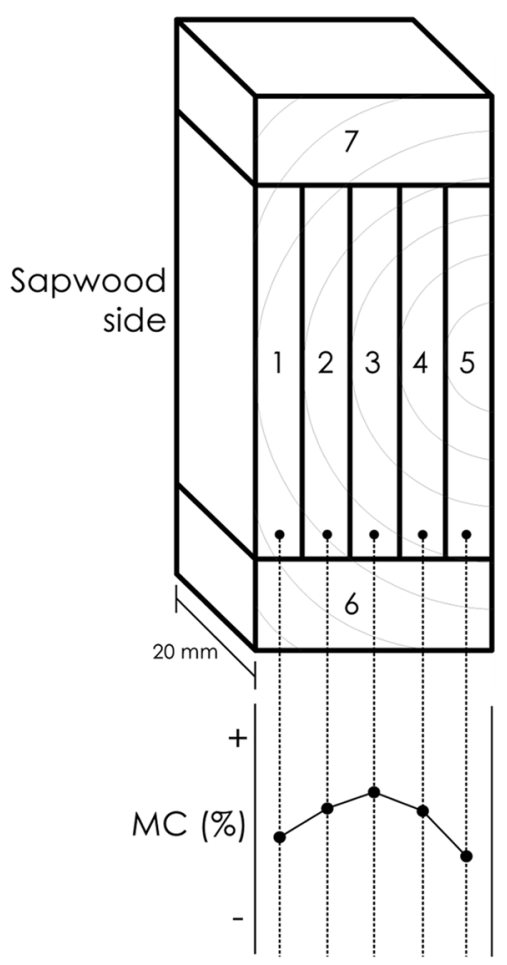

cross-section view in (b) (registered shape), and finally (d) is the MC image, i.e. the registered shape with the estimated MC in each pixel. The pixel-wise calculation of the MC is based on mass data extracted from pixels in images (b) and (c) which have the same spatial location in the specimen

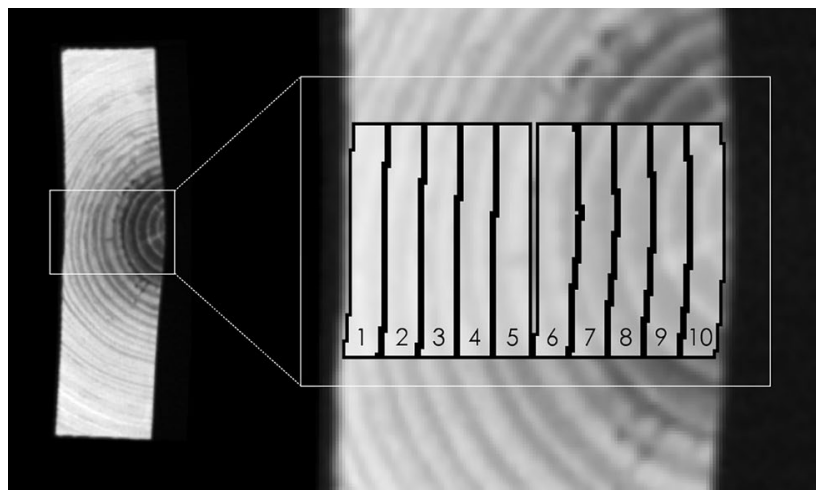

Fig. 7 Example of the sections used in this study to evaluate the differences in MC and the MC gradient in the thickness direction of the specimen. Each section was approximately $60 \mathrm{~mm}^{2}$ in cross section, and the scan was $5 \mathrm{~mm}$ in the longitudinal direction of the specimen

which is the most vulnerable part of the board during drying due to maximum tangential shrinkage, creep and risk for checking. The cross-sectional area of each section (sections numbered 1-10 in Fig. 7) was about $3 \times 20 \mathrm{~mm}^{2}$, which, with the used scanning thickness of $5 \mathrm{~mm}$, gave a

Fig. 6 Sections for the determination of the MC gradient according to Esping (1988)

from that of Esping to focus only on the central part of the specimens, radial from the pith towards the surface, studied volume of about $300 \mathrm{~mm}^{3}$ per section. The average MC of each and every section is calculated and then processed in two ways: (1) as input in Eq. (1) to calculate $\mathrm{MC}_{\text {grad }}$ for quantitative analysis of the $\mathrm{MC}$ gradient and (2) in profile plots of the MC throughout the thickness of the board. 


\section{Results and discussion}

The MC data at the pixel level was obtained from the CT images every hour during the drying and every $15 \mathrm{~min}$ utes during the conditioning regime. The MC data of the pixels located within each of the 10 sections, as shown in Fig. 7, was used to calculate the average MC of the sections and moisture profile plots across the specimen were generated. Figure 8 shows such profile plots at three key moments during conditioning: at the start of the conditioning regime, after about $7 \mathrm{~h}$ of conditioning, and at minimum $\mathrm{MC}_{\text {grad }}$, which in specimens $\mathrm{C} 1$ and $\mathrm{A} 2$ were coincident with the last and first scan during the conditioning regime, respectively.

Figure 8 shows that a drying schedule with a short drying regime (A1-C1) results in a large difference in $\mathrm{MC}$ in specimens with heartwood and sapwood when the drying schedule switches from drying to conditioning regime. The difference in $\mathrm{MC}$ is also hard to equalise during the 7 $\mathrm{h}$ conditioning regime. A longer drying regime (A2-C2) results in a flatter MC profile through the thickness of the specimens, with small differences between heartwood and sapwood.

Figure 9 shows the evolution of $\mathrm{MC}_{\text {grad }}$ during the last hours of the drying regime and the complete conditioning regime. Eq. (1) was applied to calculate $\mathrm{MC}_{\text {grad }}$, allowing for quantitative analysis of moisture gradient. The evolution of $\mathrm{MC}_{\text {grad }}$ in time can thus be studied quantitatively and a moment of minimum $\mathrm{MC}_{\text {grad }}$ across the board during the conditioning can be determined. Results show that $\mathrm{MC}_{\text {grad }}$ is lowest at $0-2 \mathrm{~h}$ of conditioning for test run No. 2 whereas it takes at least $3 \mathrm{~h}$ in test run No. 1 to achieve the minimum value of $\mathrm{MC}_{\text {grad }}$, which confirms the second hypothesis that timber dried to low MC (8\%) requires shorter conditioning time than that dried to high MC (18\%). Comparing the data regarding heartwoodsapwood proportion from Table 1 with the data of time needed to achieve the minimum $\mathrm{MC}_{\text {grad }}$ from Fig. 9, it is possible to see that, when heartwood is present, the time required to achieve the minimum value of $\mathrm{MC}_{\text {grad }}$ within a test run is shorter than when a mixture of sapwood and heartwood is present, which disproves the third hypothesis. Specimens with a large proportion of sapwood were expected to require less conditioning time, but the results show otherwise. This phenomenon is extreme in specimen A2, with heartwood present across the entire thickness of the board, which showed the minimum $\mathrm{MC}_{\text {grad }}$ precisely at the start of conditioning. This could be explained by the specimens reaching the conditioning regime with moisture gradients that are more severe with increasing amounts of sapwood, as shown in Figs. 8 and 9. A large proportion of sapwood means large amounts of water in the green state, which require longer drying times to evaporate, and thus to achieve similar profile plots and $\mathrm{MC}_{\text {grad }}$ to timber with less or no sapwood.
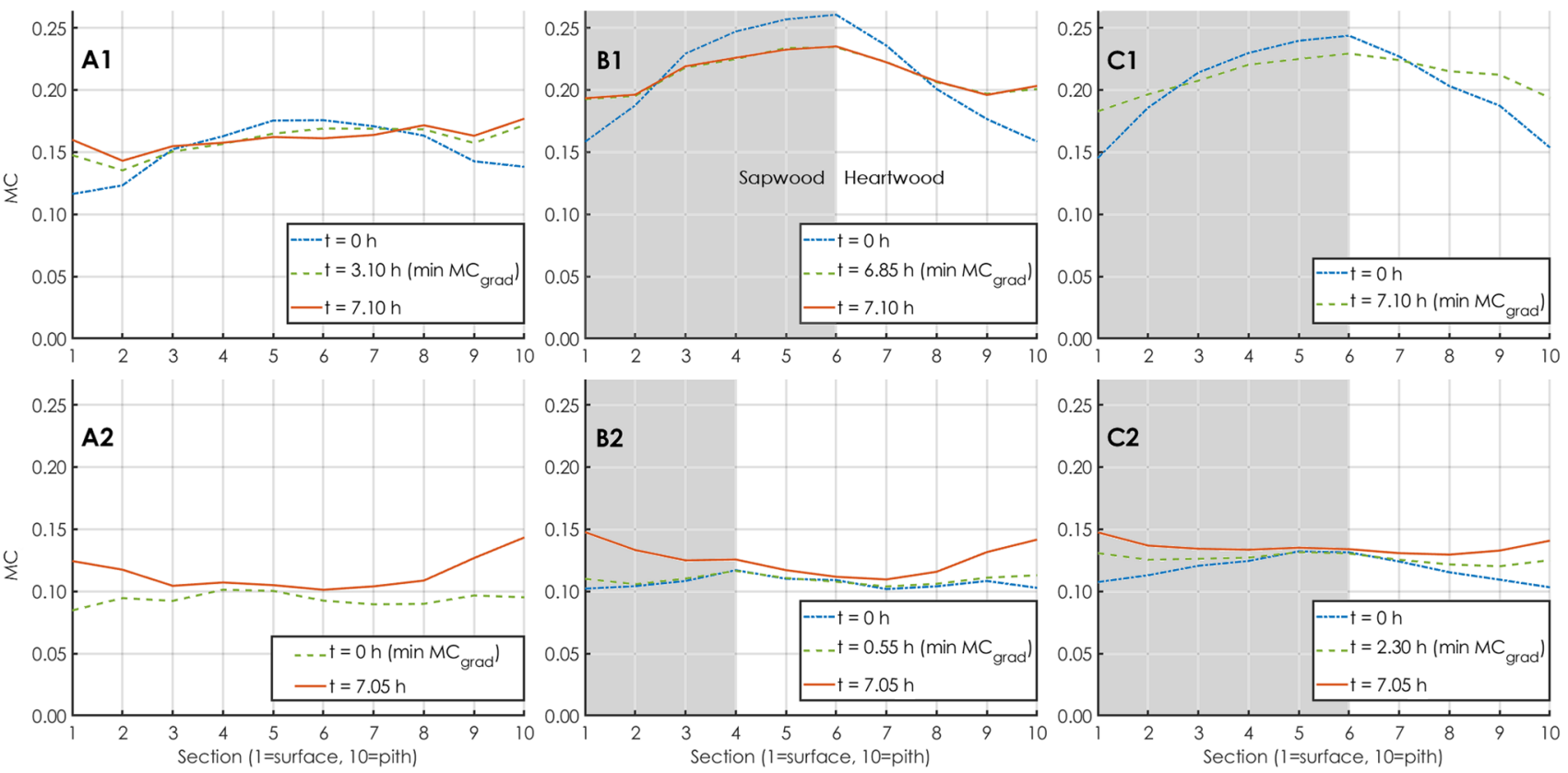

Fig. 8 Profile plots of MC throughout the thickness of the specimens (A1- C2) at three different moments during conditioning: at the start of conditioning (dash-dotted line), when the $\mathrm{MC}_{\text {grad }}$ is minimum (dashed line) and after around $7 \mathrm{~h}$ of conditioning (solid line). Sec- tions in the horizontal axis refer to the sections exemplified in Fig. 7. A grey area indicates the presence of sapwood in the section. For specimens $\mathrm{C} 1$ and $\mathrm{A} 2$ the moment of minimum gradient happens to also be the last and the first scan of the conditioning, respectively 

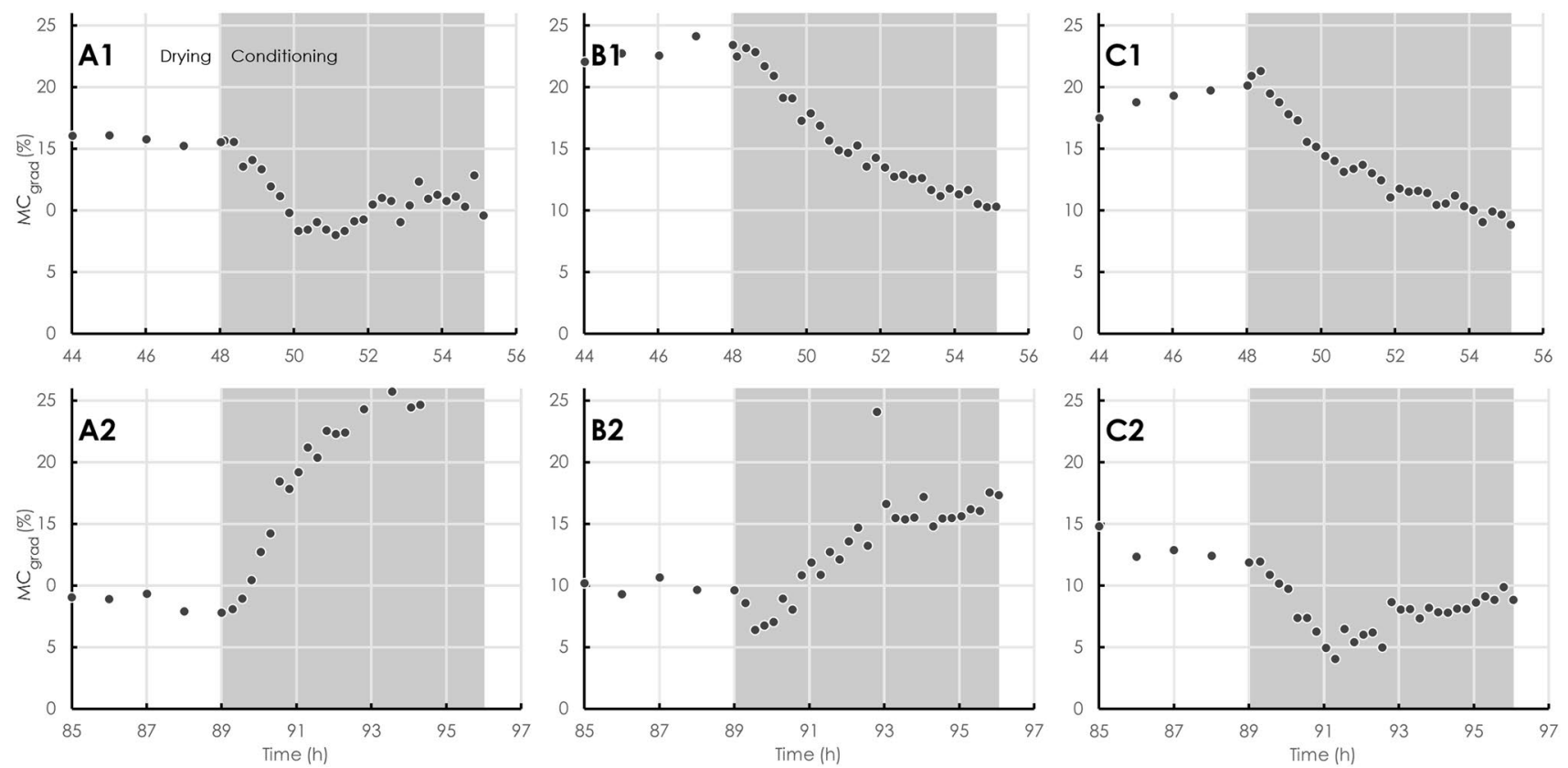

Fig. $9 \mathrm{MC}$ gradient $\left(\mathrm{MC}_{\mathrm{grad}}\right)$ as a function of time during the last hours of the drying regime (white background in the plots) and during conditioning regime (grey background)

The method described by Hansson and Fjellner (2013) has been proven suitable for studying the development of the gradient in the cross section of Scots pine timber during the drying and conditioning regimes through an analytical method based on an adaptation of Esping's practical method for its use with CT images. As one of the steps in this method is the correction of the density values in each pixel to compensate the deformation of the images due to shrinkage, the difference in volume represented by the pixels before and after registration is not expected to cause errors on the estimation of the MC. The first hypothesis, regarding the feasibility of the method, is thus confirmed.

Wood industry in northern Sweden claims that conditioning requires less time to achieve an acceptably low gradient when the timber is dried to what they consider low MC (about 8\% MC) as opposed to timber dried to higher MC (about 18\%). The hypothesis was set according to such claim and the results confirm it. It should be noted that in both test runs, the same conditions of temperature, relative humidity and air velocity are used even though the target MC is different. Probably a different drying schedule when aiming for the lower MC levels would cause the timber to reach the conditioning with a more severe gradient than what is shown here in test run No. 2. The industry usually uses a less humid environment for conditioning of low MC products than what was used here, which results in longer conditioning times. Results show that having high RH during conditioning could shorten times and give a product with equalised humidity, but the increase in energy costs needs to be considered as well. Another issue with very short conditioning is that, even if the moisture gradient is corrected, the stresses may not be if the mechano-sorptive creep (which requires the increase in moisture flow at high temperature) is not triggered or it is not large enough. Unfortunately, this is something that cannot be inspected with CT, but the issue should nevertheless be taken into account in future studies.

After the end of the conditioning process, the timber surface is expected to dry slightly during cooling, which means that a small over-conditioning would be desirable in order to compensate. From these analyses and considerations, the duration of conditioning of Scots pine in ideal laboratory conditions could be set for these dimensions, schedule and chamber size at $1-3 \mathrm{~h}$. It should be considered at this point that $\mathrm{MC}_{\text {grad }}$ by itself can be misleading because deviations in one of the sections shown in Fig. 7 would give a large value of $\mathrm{MC}_{\text {grad }}$, but that deviation could be due to errors caused by the presence of juvenile wood, which interacts with moisture differently, uncontrolled surface drying or processing errors. Ideally, both $\mathrm{MC}_{\text {grad }}$ and the visual aid of a profile plot like the ones shown in Fig. 8 should be used. This study focuses solely on the conditioning phase itself, but the history of the previous drying of the timber before reaching conditioning may also influence how timber will behave under conditioning. Thus, an analysis of the history of the specimens before conditioning should be considered in future studies.

Results show that the more sapwood is present, the longer time of conditioning is needed to achieve a minimum 
$\mathrm{MC}_{\text {grad }}$, which contradicts previous results and the hypothesis. This is an issue that should be carefully considered for future research. Eventually, clarifying the influence that the heartwood-sapwood proportion has during conditioning and possibly during drying, could provide a basis for improvement in the green sorting of the timber before drying and improve both the quality of the final product and the effectivity of the industrial process. The size of the specimens, the size of the facilities and the duration of the tests make it impractical to perform experiments with large number of specimens or to create a large database in a short time. Further studies will contribute to the collection of data that will eventually be evaluated as a whole.

\section{Conclusion}

The hypothesis that the method will provide consistent results at the pixel level that will allow the visualization and quantification of the moisture gradient and its changes during the conditioning regime has been confirmed. It has been proven that it is possible to quantify small variations of local MC and study internal MC gradient in timber during drying using a combination of medical CT, a dedicated drying chamber and a specific analytical method. Results confirm the hypothesis that when drying to a low level of MC (ca 8\%), a shorter conditioning regime is needed to achieve acceptable moisture equalisation than when drying to higher MC level (ca 18\%). The heartwood-sapwood proportion seems to influence the effectivity of conditioning. The lower the content of sapwood in the cross section is, the shorter conditioning times are required, which contradicts previous findings and the hypothesis established previously. This phenomenon is extreme if heartwood is present across the entire thickness of the board, a case that will require much shorter conditioning to equalise the MC. In such a case, there will most probably be stresses present within the board at that point, which often must be eliminated.

For the dimensions and laboratory conditions studied and considering that the final aim of a drying process should be a slight over-conditioning that will eventually equalize itself quickly. This means that Scots pine timber dried to $8 \%$ would reach an appropriate level of conditioning after about 1-3 h of conditioning time; while when dried to $18 \%$, a conditioning regime with duration of at least $3 \mathrm{~h}$ would be advised. The results suggest that it may be desirable to consider heartwood-sapwood proportion, and more specifically, the presence of heartwood in both sides of the timber, among the parameters used for green sorting before drying, even though a further analysis with larger number of samples is needed. The issue regarding the reduction in stresses remains unsolved because it is not possible to follow the evolution through the process using CT. It must be considered that this is a laboratory study and extrapolating conclusions to an industrial scale can be troublesome. The results shown by this first case study show great potential; nevertheless, the conclusions drawn from here are specific for Scots pine centre boards with green dimensions $31 \times 124 \mathrm{~mm}^{2}$ and for the drying schedules and kiln size that were used. The conclusions are limited by the small number of specimens used, thus more research, which should be specific for drying schedules that are consistent with industrial procedures and circumstances, is desired and encouraged.

Acknowledgements Open access funding provided by Lulea University of Technology.

\section{Compliance with ethical standards}

Conflict of interest On behalf of all authors, the corresponding author states that there is no conflict of interest.

Open Access This article is licensed under a Creative Commons Attribution 4.0 International License, which permits use, sharing, adaptation, distribution and reproduction in any medium or format, as long as you give appropriate credit to the original author(s) and the source, provide a link to the Creative Commons licence, and indicate if changes were made. The images or other third party material in this article are included in the article's Creative Commons licence, unless indicated otherwise in a credit line to the material. If material is not included in the article's Creative Commons licence and your intended use is not permitted by statutory regulation or exceeds the permitted use, you will need to obtain permission directly from the copyright holder. To view a copy of this licence, visit http://creativecommons.org/licenses/by/4.0/.

\section{References}

Chen G, Keey RB, Walker J (1997) Stress relief for sapwood Pinus radiata boards by cooling and steam-conditioning processes. Holz Roh- Werkst 55:351-360

Couceiro J (2016) Wood shrinkage in CT-scanning analysis. Dissertation, Luleå University of Technology.

Couceiro J, Elustondo D (2015) Implementation of computer aided yool for non-destructive X-ray measurement of moisture content distribution in wood. Pro Ligno 11:330-336

Esping B (1988) Mätning och gradering. In: Trätorkning: Torkningsfel - åtgärder. (Measuring and grading. In: Wood drying: drying errors - measure). Trätek, Stockholm, pp 70-74.

Hansson L (2007) Microwave treatment of wood. Dissertation, Luleå University of Technology.

Hansson L, Cherepanova E (2012) Determination of wood moisture properties using a CT-scanner in a controlled low-temperature environment. Wood Mat Sci Eng 7:87-92

Hansson L, Fjellner B (2013) Wood shrinkage coefficient and dry weight moisture content estimations from CT-images. Pro Ligno 9:557-561

He Q, Wang X (2015) Drying stress relaxation of wood subjected to microwave radiation. Bioresources 10:4441-4452

Li W, Van den Bulcke J, De Windt I, Van Loo D, Dierick M, Brabant L, Van Acker J (2013) Combining electrical resistance and 3-D X-ray computed tomography for moisture distribution measurements in 
wood products exposed in dynamic moisture conditions. Build Environ 67:250-259

Lindgren O (1992) Medical CT-scanners for non-destructive wood density and moisture content measurements. Dissertation, Luleå University of Technology.

McMillen JM (1958) Stresses in wood during drying. Forest Product Laboratory. https://www.fpl.fs.fed.us/documnts/fplmisc/rpt16 52.pdf. Accessed 23 Apr 2019.

Morén T (2016) The basics of wood drying: Moisture dynamics, drying methods, wood responses. Valutec AB, Skellefteå

Moren TJ, Sehlstedt-Persson M (1993) Creep response to drying of timber boards of Scots pine. For Prod J 43:58-64

Salin J (2001) Analysis and optimization of the conditioning phase in timber drying. Dry Technol 19:1711-1724

Sandberg K, Salin J (2012) Liquid water absorption in dried Norway spruce timber measured with CT scanning and viewed as a percolation process. Wood Sci Technol 46:207-219

Sehlstedt-Persson M (2001) The effect of extractive content on moisture diffusion properties for Scots pine and Norway spruce. VTT Building and Transport, Espoo
Sethy AK, Torgovnikov G, Vinden P, Przewloka S (2016) Moisture conditioning of wood using a continuous microwave dryer. Dry Technol 34:318-323

Watanabe K, Lazarescu C, Shida S, Avramidis S (2012) A novel method of measuring moisture content distribution in timber during drying using CT scanning and image processing techniques. Dry Technol 30:256-262

Wiberg P (1996) CT-scanning during drying. Moisture distribution in Pinus silvestris. In: 5th International IUFRO Wood Drying Conference Proceedings, 13-17 August, Quebec City, Canada, pp 231-235

Publisher's Note Springer Nature remains neutral with regard to jurisdictional claims in published maps and institutional affiliations. 